\title{
Comparison of the Original and Revised Structures of the Health Promotion Model in Predicting Construction Workers' Use of Hearing Protection
}

\author{
David L. Ronis, ${ }^{\dagger}$ OiSaeng Hong, ${ }^{\ddagger}$ Sally L. Lusk ${ }^{\S}$ \\ University of Michigan School of Nursing, Ann Arbor, MI 48109-0482 \\ Accepted 24 September 2005
}

\begin{abstract}
Pender's health promotion model (HPM) has been revised, including substantial changes in its structure. The purpose of this study was to compare the fit and predictive usefulness of the original and revised structures of the HPM as applied to the use of hearing protection devices by 703 construction workers. Structural equation modeling was used to evaluate the two alternative forms of the model. Both forms of the model fit well, with the revised structure having a better fit and explaining more of the variance in use of hearing protection ( $28 \%$ vs. $18 \%$ ). Results support the revised structure of the health promotion model (HPM) over the original form, and indicate it may be useful in understanding and predicting use of hearing protection. (c) 2006 Wiley Periodicals, Inc. Res Nurs Health 29:3-17, 2006
\end{abstract}

Keywords: health behavior; models; theoretical; ear protective devices

More than 1 of 10 Americans are exposed to hazardous levels of noise at work (National Institute for Occupational Safety and Health [NIOSH], 1996a), and about 9 million Americans have noise-induced hearing loss, an irreversible condition that negatively affects quality of life (National Institutes of Health, 1990). This damage to hearing can be prevented by wearing hearing protection devices, such as earplugs, when exposed to loud noise (National Institute for Occupa- tional Safety and Health [NIOSH], 1996b). Yet few workers use hearing protection consistently enough to prevent hearing loss (Hong, Wilber, \& Furner, 1998; Lusk, Kerr, \& Kauffman, 1998).

Reviewers of occupational health and safety intervention research, as well as behavioral theorists, strongly recommend use of conceptual or theoretical frameworks as guides for behavioral intervention programs (McAfee \& Winn, 1989). Conceptual models provide guidance for selecting

Contract grant sponsor: National Institute for Occupational Safety and Health; Contract grant number: R01 OH03136. Contract grant principal investigator: Sally L. Lusk.

The contents are solely the responsibility of the authors and do not necessarily represent the official views of NIOSH.

Correspondence to OiSaeng Hong, PhD, RN, University of Michigan School of Nursing, 400 N. Ingalls, Room 3182, Ann Arbor, MI 48109-0482.

$\dagger$ Associate Research Scientist (affiliated with the U.S. Department of Veteran Affairs).

${ }_{\ddagger}^{\ddagger}$ Assistant Professor.

${ }^{\S}$ Professor Emerita.

Published online in Wiley InterScience (www.interscience.wiley.com)

DOI: 10.1002/nur.20111 
content of interventions (Lusk, Kerr, Ronis, \& Eakin, 1999; Lusk, Ronis, \& Kerr, 1995) and enhance opportunities to replicate approaches, thus building a scientific basis for strategies for behavioral change in the workplace. Yet the vast majority of worksite studies do not have theoretical models guiding their interventions.

The primary purpose of the study reported here is to advance theoretical understanding of healthrelated behaviors by comparing the fit and predictive utility of the original (Pender, 1987) and revised (Pender, 1996; Pender, Murdaugh, \& Parsons, 2002) structural forms of the health promotion model (HPM) as a model of construction workers' use of hearing protection. The HPM was derived from expectancy-value theory (e.g., Fishbein \& Ajzen, 1975) and social cognitive theory (Bandura, 1986). The key ideas from expectancy-value theory incorporated in the HPM are that a person's decision to take action will be determined by the expected outcomes of the action and by the person's evaluation of those outcomes. People are hypothesized to take action if the expected positive outcomes (benefits) of the action outweigh the expected negative outcomes (barriers). To those ideas, social cognitive theory adds an emphasis on feelings of self-efficacy (i.e., persons' confidence that they can carry out the action). Even if the benefits of an action outweigh the barriers, people will not try to take an action unless they believe they can carry it out. Social cognitive theory also contributes to the HPM an emphasis on social influences.

Although the HPM was developed to explain health-promoting behaviors, such as exercise, it also can be used for health-protecting behaviors (Pender, 1996; Pender et al., 2002). The behavior of interest in the study reported here-use of hearing protection devices-requires repeated action by the individual worker to prevent consequences that will be apparent many years later. Thus, it is similar to other health-promoting behaviors, such as participating in a consistent exercise program that leads to long-term cardiovascular benefits. Further support for the use of the HPM in our study of construction workers was its excellent predictive power for factory workers' use of hearing protection, where variables from the HPM accounted for about one-half of the variance in their use (Lusk, Ronis, Kerr, \& Atwood, 1994).

In the original structure of the HPM (Pender, 1987), predictors of health-related behaviors were divided into two categories: modifying factors and cognitive-perceptual factors. As shown in Figure 1, the structure of the original model was that: (a) modifying factors directly influence cognitive-perceptual factors; (b) cognitive-perceptual factors directly influence health-related behavior; and (c) modifying factors do not directly influence health-related behavior.

The revised form of the HPM (Pender, 1996; Pender et al., 2002) includes primarily the same factors as the original model but organizes them in a different structure (Figure 2). The predictors of health-related behaviors are divided into two categories: (a) individual characteristics and experiences and (b) behavior-specific factors. In contrast with the original version, all predictor variables directly influence health-related behavior. The individual characteristics and experiences also directly influence the behavior-specific factors. Although the formal structure of the model does not demonstrate this, the revised model emphasizes the behavior-specific factors more than the individual characteristics and experiences as predictors of, and influences on, health-related behavior. For complete descriptions of both versions of the HPM, see Pender (1996). The current paper focuses on whether these changes in the structure of the HPM improve the model's ability to predict and explain use of hearing protection devices.

Published reports present tests only of the original form of the HPM, and results have varied. In Pender's program of research, almost all of the proposed paths in the HPM were significant predictors of exercise performance in one or more of four samples of adults (Pender, 1996). Conducting secondary analyses on data from the National Survey of Personal Health Practices and Consequences, Johnson, Ratner, Bottorff, and Hayduk (1993), and Ratner, Bottorff, Johnson, and Hayduk (1994), selected items to measure concepts in the HPM. These researchers found direct effects of modifying factors on various health-promoting behaviors rather than the indirect effects proposed by the original structure of the HPM. Thus, they questioned the validity of the model. The basis for some of the Johnson et al. and Ratner et al. concerns about the HPM have been overcome in the revised structure of the model (Pender, 1996; Pender et al., 2002), which includes direct relationships between the former modifying factors and the behavior of interest.

In studies by Kerr, Lusk, and Ronis (2002), Lusk, Ronis, and Hogan (1997), and Lusk et al. (1994), variables from the HPM accounted for up to half of the variance in the use of hearing protection devices. Yet in these studies an exploratory form of the HPM accounted for more variance than the original theoretical structure. This exploratory variation allowed direct paths 


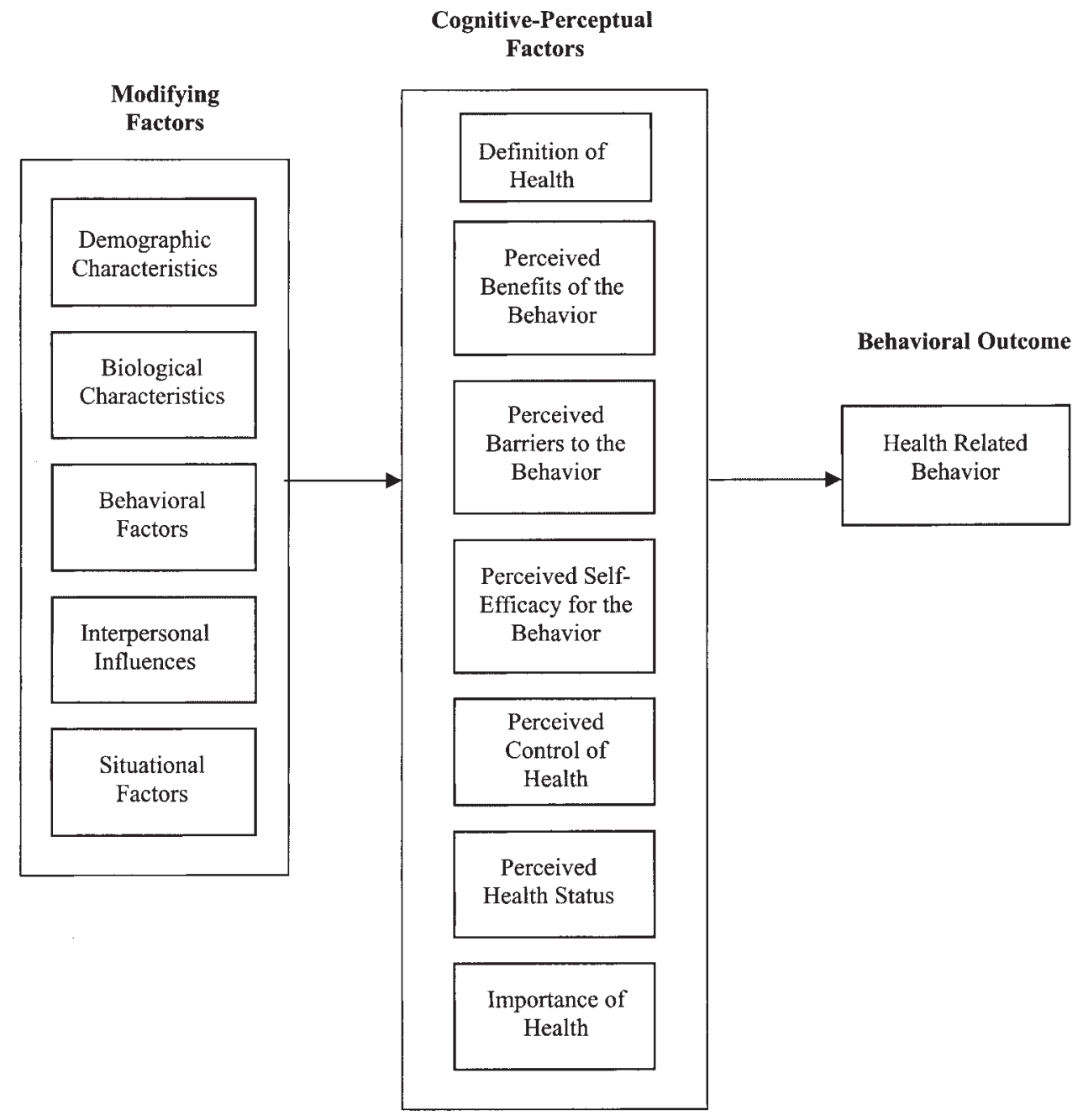

FIGURE 1. Original structure of the health promotion model (Pender, 1987).

from all factors to the behavior, more closely approximating the revised structure of the HPM. Accordingly, although not directly comparing the two structures, several investigative teams have suggested that the revised structure may be superior. To assess better the efficacy of the two alternative structures of the HPM, a careful comparison is needed. In this study, we compared the fit and predictive power of the two alternative structural forms of the HPM as applied to construction workers' use of hearing protection.

\section{METHODS}

\section{Research Design and Participants}

The analyses reported here are based on post-test data collected in a hearing protection intervention study from a sample of Midwestern construction workers (carpenters, operating engineers, and plumber/pipefitters), and a national sample of plumber/pipefitter trainers. The current analysis is best viewed as a secondary analysis of data from the intervention study. Comparison of the forms of the original and revised HPM was not one of the aims of the original study. In fact, the original study was being conducted before the publication of the revised model, and the study did not include measures of factors that were new additions to the revised model. In the study, a theory-based intervention based on significant predictors of construction workers' use of hearing protection was used (Lusk, Kerr, et al., 1999). The intervention program consisted of a video, live instruction, guided practice, written handouts, and sample hearing protection devices 
Behavioral-Specific Factors

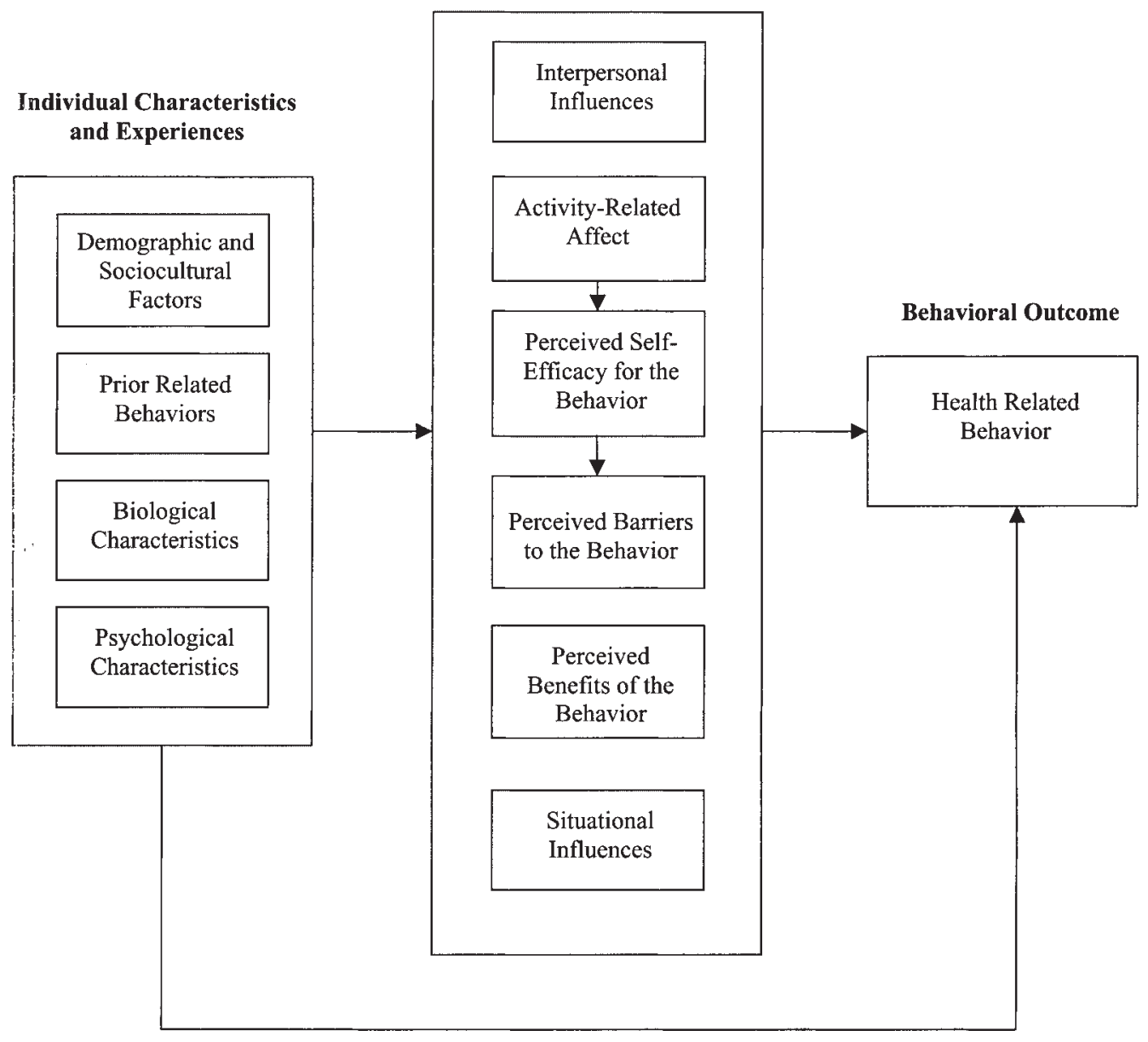

FIGURE 2. Revised structure of the health promotion model (Pender, 1996; Pender et al., 2002).

presented in group settings. See Lusk, Hong, et al. (1999) for a more extensive description of the intervention.

A Solomon Four-Group Design (Campbell \& Stanley, 1966) was used to evaluate the effect of the intervention and the effect of pre-testing on the use of hearing protection among construction workers. Lusk, Hong, et al. (1999a) found that the intervention increased the use of hearing protection devices but that pre-testing had no effect. Post-test data were chosen for analysis because there were a greater number of cases for it (only half the participants had a pre-test in the Solomon Four-Group Design) and to show how the model explained or reflected the effect of the intervention.

Of 1,501 workers recruited for either the pretest survey or hearing protection training in 1995 , 1,028 participated in post-test data collection in
1996 yielding a 68\% response rate. For the purpose of the present study, only those workers who reported that they were exposed to high noise and provided data for all relevant variables in posttest data collection were included in the analysis $(n=703)$. Exposure to high noise was indicated by respondents" answers to "Do you spend some of the time at your job sites working in high noise?" We surmised that because hearing protection devices are needed only during exposure to high noise, this was the most appropriate group for analysis. The final sample consisted of 138 carpenters, 234 operating engineers, 182 plumber/pipefitters, and 149 plumber/pipefitter trainers. Descriptive statistics on demographics and use of hearing protection devices are provided in Table 1. Because the four trade groups differed substantially on the use of hearing protection $F(3,699)=20.05, p<.001$, dummy variables 
Table 1. Demographic Characteristics and Use of Hearing Protection of Noise-Exposed Construction Workers at Post-Intervention $(n=703)$

\begin{tabular}{|c|c|c|c|c|}
\hline & \multirow[b]{2}{*}{$\begin{array}{l}\text { Carpenters } \\
(n=138)\end{array}$} & Regional & \multirow[b]{2}{*}{$\begin{array}{l}\text { Plumber/Pipefitters } \\
\qquad(n=182)\end{array}$} & \multirow{2}{*}{$\begin{array}{l}\text { National } \\
\text { Plumber/Pipefitter } \\
\text { Trainers }(n=149)\end{array}$} \\
\hline & & $\begin{array}{l}\text { Operating Engineers } \\
\qquad(n=234)\end{array}$ & & \\
\hline & Mean $(S D)$ & Mean (SD) & Mean (SD) & Mean $(S D)$ \\
\hline $\mathrm{Age}^{*}$ & $27(6)$ & $43(8)$ & $31(7)$ & $41(7)$ \\
\hline Year in trade* & $4(4)$ & $19(8)$ & $5(5)$ & $19(8)$ \\
\hline \multirow{2}{*}{$\begin{array}{l}\text { Percent of time } \\
\text { using hearing } \\
\text { protection* }\end{array}$} & $37(33)$ & $62(34)$ & $43(32)$ & $51(34)$ \\
\hline & $\%$ & $\%$ & $\%$ & $\%$ \\
\hline \multicolumn{5}{|l|}{ Sex } \\
\hline Female & 3 & 2 & 3 & 1 \\
\hline \multicolumn{5}{|l|}{ Ethnicity } \\
\hline White & 88 & 94 & 94 & 96 \\
\hline $\begin{array}{l}\text { Education } \\
\text { beyond high } \\
\text { school* }\end{array}$ & 21 & 24 & 25 & 70 \\
\hline $\begin{array}{l}\text { Exposed to } \\
\text { intervention }\end{array}$ & 51 & 50 & 53 & 52 \\
\hline
\end{tabular}

*Significantly different among four groups, $p<.05$.

indicating trade group were included in the analyses.

Missing data were spread rather evenly across the variables. Participants who were excluded were different from those included on a few variables besides noise exposure: age, minority group identification, trade group, years in trade, benefits, value of use, and self-efficacy $(p<.05)$. Participants excluded due to lack of noise exposure or missing data were more likely to be older, of an ethnic minority group, in a profession other than plumber/pipefitter, and to have had longer experience in the trade. They also had lower benefits, value of use, and self-efficacy. Notably, those excluded did not differ from those included on the use of hearing protection or on the many other variables in the study. Accordingly, the included sample was different from but generally similar to the whole population except for having noise exposure.

\section{Measures}

Respondents completed questionnaires about the use of hearing protection, demographics, and almost all factors from either the original or the revised form of the HPM, as they apply to the use of hearing protection (see Table 2). The scales in the questionnaire had demonstrated good reliability in previous studies (Kerr et al., 2002; Lusk et al., 1994, 1997). All measures had acceptable reliability coefficients (alpha $=.73-.95)$ for the current sample (see Table 2). All variables are described in detail below, with the number of items, range of scales (e.g., 1-6), and alpha coefficients for scales presented in Table 2. Each variable in the study was part of both versions of the HPM except perceived control of health, which was only part of the original version.

\section{Outcome Variable}

The outcome variable in this study-use of hearing protection-was defined as wearing earplugs or earmuffs. This variable was measured by workers' self-report on five questions regarding the percentage of time $(0 \%-100 \%)$ that they used hearing protection at two job sites (most recent and previous) and during three time periods (the past week, past month, and past three months). Because the items were strongly correlated (alpha $=.95)$, their average score was used as the outcome measure.

\section{Predictors}

Demographic characteristics. A number of demographic characteristics, including age, years in trade, sex, minority status (non-white and/or 
Table 2. Health Promotion Model (HPM) Components and Scales

\begin{tabular}{|c|c|c|c|c|c|}
\hline HPM Component & Scale & $\begin{array}{l}\text { Number } \\
\text { of Items }\end{array}$ & Range & Mean $(S D)$ & Alpha \\
\hline \multirow[t]{3}{*}{ Interpersonal influences } & Social norms & 4 & $1-3$ & $2.33(.50)$ & .73 \\
\hline & Interpersonal support & 8 & $1-3$ & $1.56(.45)$ & .87 \\
\hline & Social modeling & 2 & $1-5$ & $2.65(1.07)$ & .79 \\
\hline Situation factors/influences & $\begin{array}{l}\text { Accessibility of hearing } \\
\text { protection }\end{array}$ & 8 & $1-6$ & $3.39(1.29)$ & .83 \\
\hline Perceived control of health & Health competence & 8 & $1-6$ & $4.33(.86)$ & .82 \\
\hline \multirow[t]{2}{*}{ Definition of health } & Health conception-clinical & 7 & $1-6$ & $5.13(.97)$ & .88 \\
\hline & $\begin{array}{l}\text { Health conception-overall } \\
\text { wellness }\end{array}$ & 9 & $1-6$ & $4.92(.90)$ & .88 \\
\hline Perceived hearing health & Self-rated hearing health & 4 & $1-3$ & $2.27(.44)$ & .74 \\
\hline Perceived self-efficacy & $\begin{array}{l}\text { Self-efficacy in use of } \\
\text { hearing protection }\end{array}$ & 10 & $1-6$ & $4.41(.69)$ & .75 \\
\hline \multirow[t]{2}{*}{ Perceived benefits } & Benefits of hearing protection & 12 & $1-6$ & $4.86(.63)$ & .77 \\
\hline & $\begin{array}{l}\text { Value of use of hearing } \\
\text { protection }\end{array}$ & 5 & $0-100$ & $87.33(11.02)$ & .89 \\
\hline Perceived barriers & $\begin{array}{l}\text { Barriers to use of hearing } \\
\text { protection }\end{array}$ & 12 & $1-6$ & $2.85(.87)$ & .83 \\
\hline Health related behavior & Use of hearing protection & 5 & $0-100$ & $49.87(34.48)$ & .95 \\
\hline
\end{tabular}

Hispanic), education, and trade group, were measured by single items.

Interpersonal influences. Perceptions regarding others' (family, friends, supervisors, and coworkers) behavior and attitudes on the use of hearing protection devices were measured using three scales (social norms, interpersonal support, and social modeling). Social norms were measured by items asking about respondents' beliefs regarding how much others think they should wear hearing protection (not at all to a lot). Interpersonal support was measured by questions about how much others encourage or praise respondents for using hearing protection. Social modeling was measured by questions about how much respondents believed that their supervisor and the coworker they spend the most time with use hearing protection when exposed to noise (never to always).

Situational factors/influences. Perceptions of accessibility of hearing protection devices were measured by questions asking workers how much they agreed with statements such as "earplugs are available to pick up at my job sites." Responses for this measure and several other measures were given on a 6-point scale ranging from strongly disagree to strongly agree, hereafter called the 6-point agreement scale.

Perceived control of health. The extent to which individuals feel in control of their health was measured by the Perceived Health Competence Scale developed and validated by Smith, Wallston, and Smith (1995). An example of an item in the scale is: "I handle myself well with respect to my health" (6-point agreement).

Definition of health. An individual's perception of the meaning of health was measured using a reduced form of Laffrey (1986) Health Conception Scale. The revision process is reported in detail elsewhere (Lusk, Kerr, \& Baer, 1995a). The scale consisted of two subscales: clinical health and overall wellness. Examples of items from the clinical health and the overall wellness subscales are "being free from symptoms of disease" and "feeling great—on top of the world," respectively (6-point agreement). There is mixed evidence on the subscale structure of the health conception scale. A structural equation model analysis by Ratner, Bottorff, Johnson, and Hayduk (1996) yielded evidence that neither the clinical nor wellness subscales were one-dimensional. On the other hand, Hong, Lusk, and Klem (2000) replicated the two-factor structure (clinical and wellness) previously found by Lusk, Kerr, et al. (1995) and used in the current analyses. Analyses of the current data indicate high reliability of both subscales (Table 2). The two subscales also had adequate discriminant validity with respect to all other measures used in the study. Despite the complexities found by Ratner et al. (1996), the two-factor structure provides sufficient detail for the current study.

Perceived hearing health status. The individual's conception of current hearing health was measured on a 3-point scale. A sample item from this scale is: "Would you say that your hearing 
health is better, about the same, or not as good as most people your age?"

Perceived self-efficacy. A judgment of the individual's abilities to perform the activity was measured by the Self-Efficacy in Use of Hearing Protection Scale developed for this program of research (6-point agreement). An example of an item from this scale is: "I am sure I can use my hearing protection so it works effectively."

Perceived benefits. Beliefs regarding the positive results of the behavior were measured by two scales (Benefits of use and Value of use of hearing protection) developed for this program of research. A sample item from the Benefits scale is: "Wearing hearing protection protects me against hearing loss from noise exposure" (6-point agreement). The measurement of Value of use of hearing protection was a 5-item $100 \mathrm{~mm}$ visual analogue scale used to assess the degree of importance of such items as "protect my hearing." Anchors of the scale were slightly important and highly important. Answers were recorded in millimeters.

Perceived barriers. Perceptions of inconvenience, discomfort, difficulty of engaging in the behavior, and interference with communication were measured by the Barriers to Use of Hearing Protection Scale developed for this program of research. An example of an item in this scale is "Hearing protection keeps me from hearing what I want to hear" (6-point agreement).

Exposure to the intervention. This was included as a dichotomous predictor variable.

\section{Analysis}

Data were analyzed by maximum-likelihood estimation of structural equation models using the EQS program (Bentler, 1995). Analyses were conducted on the covariance matrix of 703 cases with data on all relevant variables.

Confirmatory factor analysis (CFA) was conducted to evaluate the measurement of the constructs and the correlations among them. In the CFA and the other structural equation models, the multiple item scale of each predictor construct was randomly divided into two subscales (Floyd \& Widaman, 1995; Marsh, Antill, \& Cunningham, 1989). These subscales were used as the measures of the constructs, allowing measurement errors for these constructs to be estimated and separated from the assessment of the relationships among constructs. Based on computer simulation of confirmatory factor analysis models containing normally distributed variables, Marsh, Hau, Balla, and Grayson (1998) have recommended analysis of the individual items rather than subscales as we have used. They acknowledge that results from analysis are likely to be similar using the two approaches and that more realistic data may benefit from using subscales (or parcels as they called them). Our decision to use the subscales resulted from a practical advantage. The covariance matrix based on individual items would have been based on 103 items so would contain about 5,000 covariances. In contrast the matrix used in the analysis was only based on 34 variables and contained only about 500 covariances. This was much more usable. The remaining predictors (age, sex, minority status, education, trade group, years in trade, and exposure to the intervention) were measured by single items. These single item measures were judged to be highly reliable because they are reports of facts that workers are commonly asked about and they are well represented in memory. In the CFA, all factors were allowed to correlate with each other.

The outcome variable-frequency of use of hearing protection when in high noise-was measured as the mean of five highly correlated items. In the structural equation analysis, this mean score was modeled as if it was measured without error. This approach to modeling means that the relationships of predictor variables with use of hearing protection will be slightly underestimated by correlations and standardized path coefficients; however, the relative strength of relationships is correctly represented. Because modeling the predictor variables as if they had been measured without error can lead to either underestimates or overestimates of relationships, this was only done for the highly reliable single item measures (Bollen, 1989).

\section{RESULTS}

The CFA model was rejected as a perfect fit to the data, $\chi^{2}(306)=596.6, p<.001$. Yet because the $\chi^{2}$ test of perfect fit is sensitive to sample size and non-normality of the data (Hu \& Bentler, 1999) practical measures that indicate how well a model fits, rather than whether it fits perfectly, have been developed. Some of these, including the nonnormed fit index (NNFI) and the comparative fit index (CFI), can be interpreted as estimates of the proportion of the information in the covariance matrix that is explained by the model. Values of .95 and higher on these measures are considered to indicate good fit (Hu \& Bentler, 1999). In contrast, the root mean square error of approximation 
(RMSEA) is a measure of deviation from the model, for which values between 0 and .06 are considered to indicate good fit ( $\mathrm{Hu} \&$ Bentler, 1999). These practical measures indicated a reasonably good fit of the CFA model $(\mathrm{NNFI}=.95 ; \mathrm{CFI}=.97$; $\mathrm{RMSEA}=.037)$. Modification indices pointed to some problems with the measurement model for benefits and high collinearity $(r=-.73)$ between benefits and barriers. Because the study included another scale (value) that was conceptually almost identical to benefits, but without such problems, the benefits scale was dropped and the measurement model was re-estimated.

The second CFA model fit imperfectly but well: $\chi^{2}(264)=458.9, p<.001 ; \mathrm{NNFI}=.96 ; \mathrm{CFI}=.98$; RMSEA $=.032$. Modification indices did not suggest the need for changes. But there were high correlations among some factors that probably would have caused collinearity problems in further analyses. Specifically, age and years in trade correlated .88 and there were high correlations $(.57-.74)$ among the interpersonal influence variables (social norms, interpersonal support, and social modeling). To avoid collinearity problems, age, social norms, and interpersonal support were dropped, leaving years in trade and social modeling as the factors representing these two domains. The decisions on which of the collinear variables to drop were made without examining the relations of these variables with use or other variables, and were based on substantive and measurement considerations. Specifically, years in trade seemed more directly relevant than age to behavior at work. We chose the modeling variable (which potentially is a report of direct observation of repeated behavior) because the norm measure required participants to report their opinions about other people's opinions and the interpersonal support measure concerned behaviors that we suspected were uncommon.

The final CFA model fit even better: $\chi^{2}(180)=300.4, p<.001 ; \mathrm{NNF}=.97 ; \mathrm{CFI}=.98 ;$ RMSEA $=.031$. In addition, all measures loaded significantly on their factors $(p<.001)$ and modification indices did not suggest any meaningful revisions. These results provided evidence for the convergent validity of the two subscales used as indicators of each construct and for the discriminant validity of subscales assessing different constructs. The correlation matrix among factors derived from this analysis is presented in Table 3.

The next steps in the analysis were to estimate and test full structural equation models incorporating the measurement model of the final CFA model in addition to paths among factors hypothesized by the original and revised structures of the HPM.

\section{Path Model of Original HPM Structure}

In the original HPM (Pender, 1987), (a) modifying factors directly influence cognitive-perceptual factors; (b) cognitive-perceptual factors directly influence health-related behavior; and (c) modifying factors do not directly influence health-related behavior. In the current study, the modifying factors were sex, minority status, trade group, education, intervention, situational factors (accessibility of hearing protection devices), social modeling, and years in trade. The analysis did not include any measure of behavioral factors, such as prior use of hearing protection. The cognitive-perceptual factors were: (a) definition of health (clinical health and overall wellness); (b) benefits (assessed by the value of use scale); (c) barriers; (d) self-efficacy; (e) perceived control of health (health competence); and (f) perceived hearing health. The statistically significant paths from the model are shown in Figure 3. Factors without statistically significant paths are not included in figures showing significant paths. There were statistically significant direct paths to use from clinical definition of health, value of use, barriers, self-efficacy, and health competence. The intervention increased use of hearing protection via significant paths to barriers and self-efficacy.

Although the model could be rejected as an exact fit to the data, $\chi^{2}(190)=386.6, p<.001$, the practical measures suggest that the fit was reasonably good $(\mathrm{NNFI}=.95 ; \mathrm{CFI}=.97 ; \mathrm{RMSEA}=$ .038). The model accounted for $18 \%$ of the variance in use of hearing protection (see Table 4 ).

\section{Path Model of Revised HPM Structure}

In the revised HPM (Pender, 1996; Pender et al., 2002), the variable perceived control of health was dropped. The other variables have been organized differently, with behavior-specific variables emphasized as direct influences on behavior although individual characteristics and experiences influence the behavior-specific cognitions. The revised model also allows the individual characteristics and experiences directly to influence behavior. In addition, the revised model posits that high perceived self-efficacy for the behavior reduces perceived barriers to the behavior. 


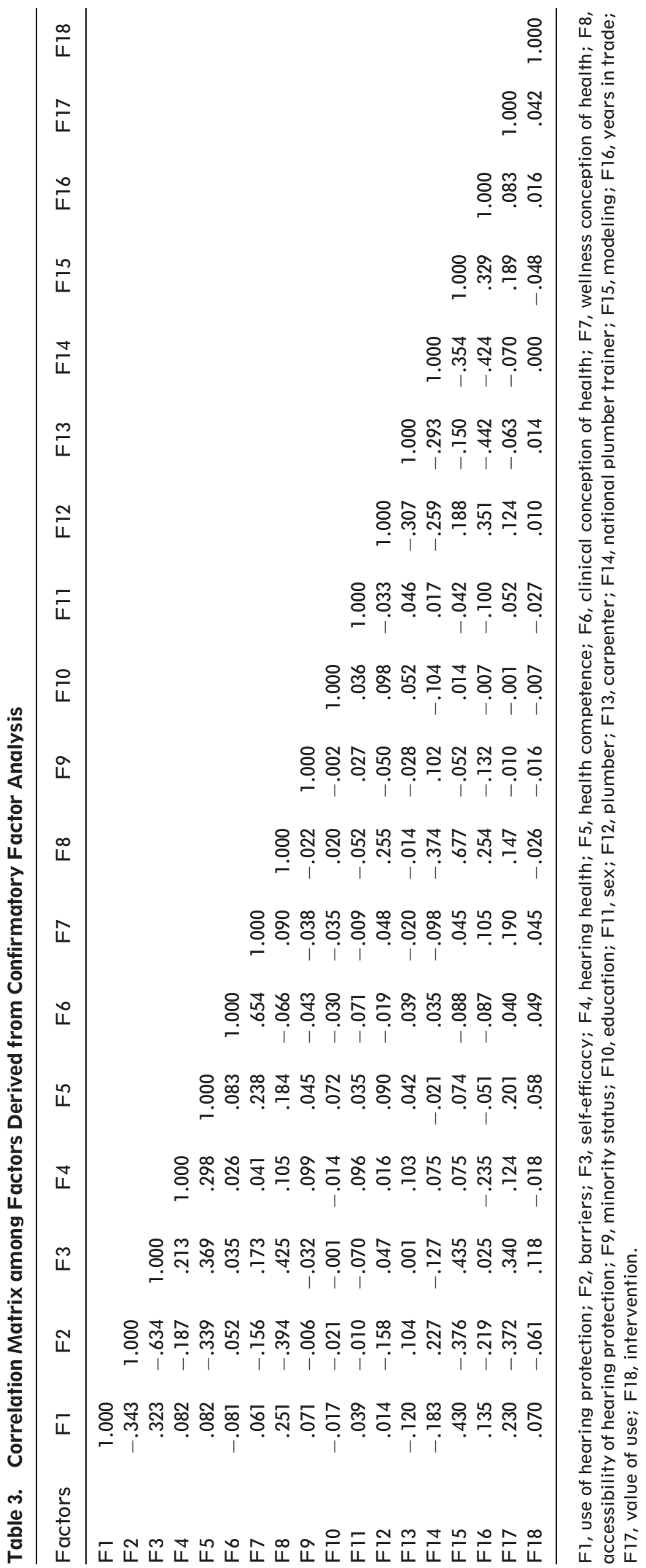




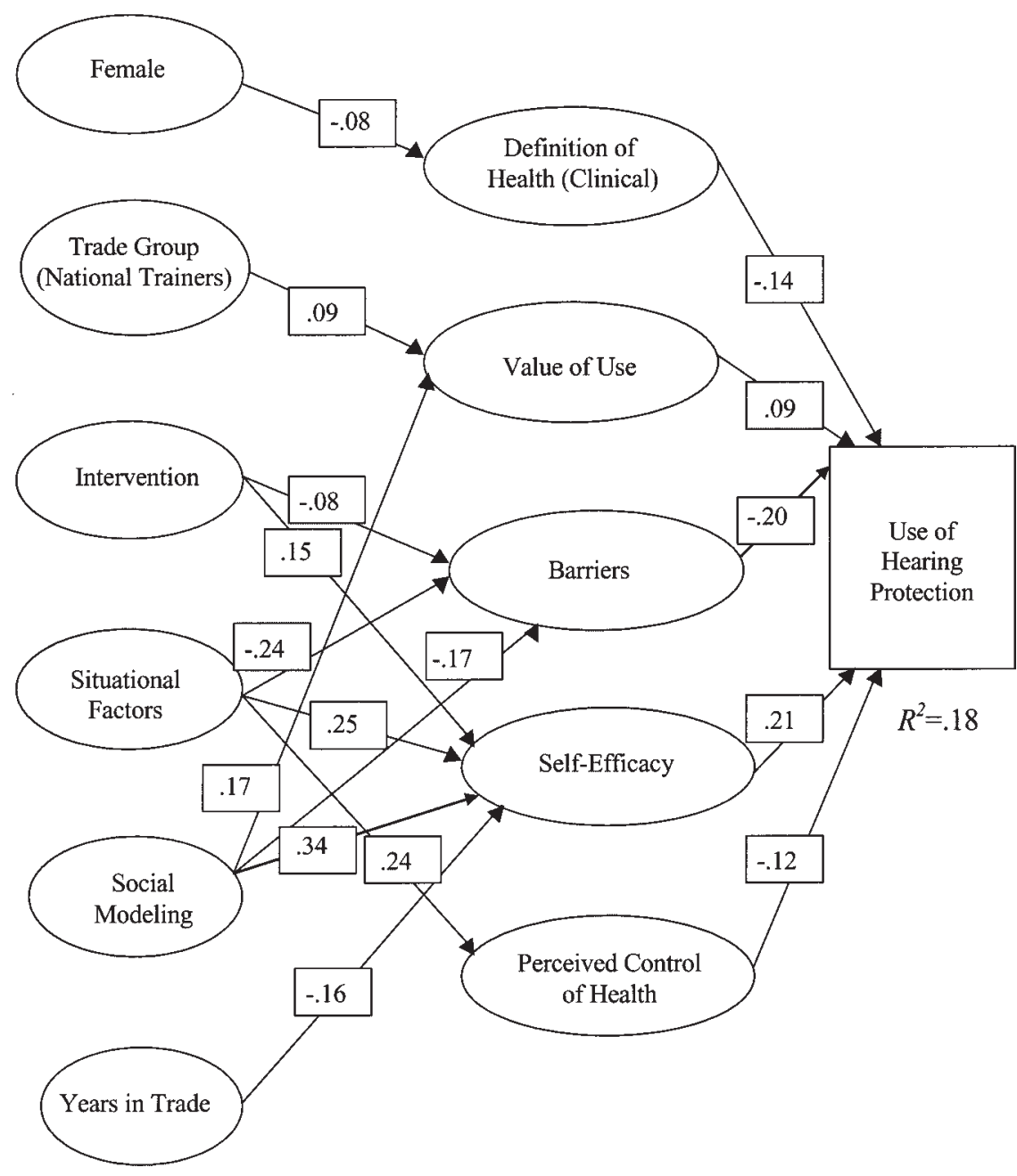

FIGURE 3. Significant paths (original structure). Path coefficients are standardized and enclosed in boxes.

In this analysis, the individual characteristics and experiences were trade group, sex, minority status, education, exposure to the intervention, years in trade, perceived hearing health, and definition of health. The behavior-specific factors were social modeling, self-efficacy, barriers, benefits (value of use), and situational factors specific to use of hearing protection (availability and accessibility of hearing protection). Although it is part of the revised HPM, this study did not include a measure of activity-related affect, as these data were collected before the revision of the HPM.

The statistically significant paths from the estimation of the revised form of the HPM are

Table 4. Fit of Structural Equation Models

\begin{tabular}{lcccccc}
\hline Model & $D f$ & $\chi^{2}$ & NNFI & CFI & RMSEA & $R^{2}$ \\
\hline Original HPM structure & 190 & 386.6 & .95 & .97 & .038 & .18 \\
Revised HPM structure & 148 & 252.4 & .97 & .98 & .032 & .28 \\
Revised HPM structure, constrained & 159 & 288.4 & .96 & .98 & .034 & .26 \\
\hline
\end{tabular}

NNFI, non-normed fit index; CFI, comparative fit index; RMSEA, root mean square error of approximation; HPM, health promotion model. 
shown in Figure 4. Again, the revised model could be rejected as an exact fit to the data, $\chi^{2}(148)=252.4, p<.001$. The practical measures indicate good fit $(\mathrm{NNFI}=.97$; $\mathrm{CFI}=.98$; RMSEA $=.032$ ). The model accounted for $28 \%$ of the variance in use of hearing protection (see Table 4). There were statistically significant direct paths to use from social modeling, barriers, value of use, trade group, minority status, years in trade, and from the intervention. The strongest of these paths was from social modeling. The intervention also increased use of hearing protection via an indirect effect mediated by significant paths from the intervention to self-efficacy and from selfefficacy to barriers.

\section{Path Model of Revised HPM Structure: Constrained}

The fit of the original and revised forms of the HPM can be compared descriptively using the proportion of variance in use accounted for and the practical measures of fit. The revised model fit better on all of these measures, with a particularly notable improvement in the proportion of variance accounted for $(28 \%$ vs. $18 \%)$.

Every factor in the structure of the revised HPM is allowed directly to influence the health related behavior. This makes it easier for the revised model successfully to account for variability in behavior. The analysis of the revised form of the HPM had 16 direct paths to hearing protection use, although the analysis of the original form of the HPM had seven direct paths to use. To determine whether it was simply the increased number of predictors with direct paths to use of hearing protection that produced the improved $R^{2}$ rather than the restructuring of the model, which gives greater emphasis to the behavior-specific predictor variables, we also analyzed a more constrained variation of the revised form of the HPM. The constrained variation of the revised HPM retained the paths from the behavior-specific variables to use of hearing protection and the paths from the individual characteristics to the behavior

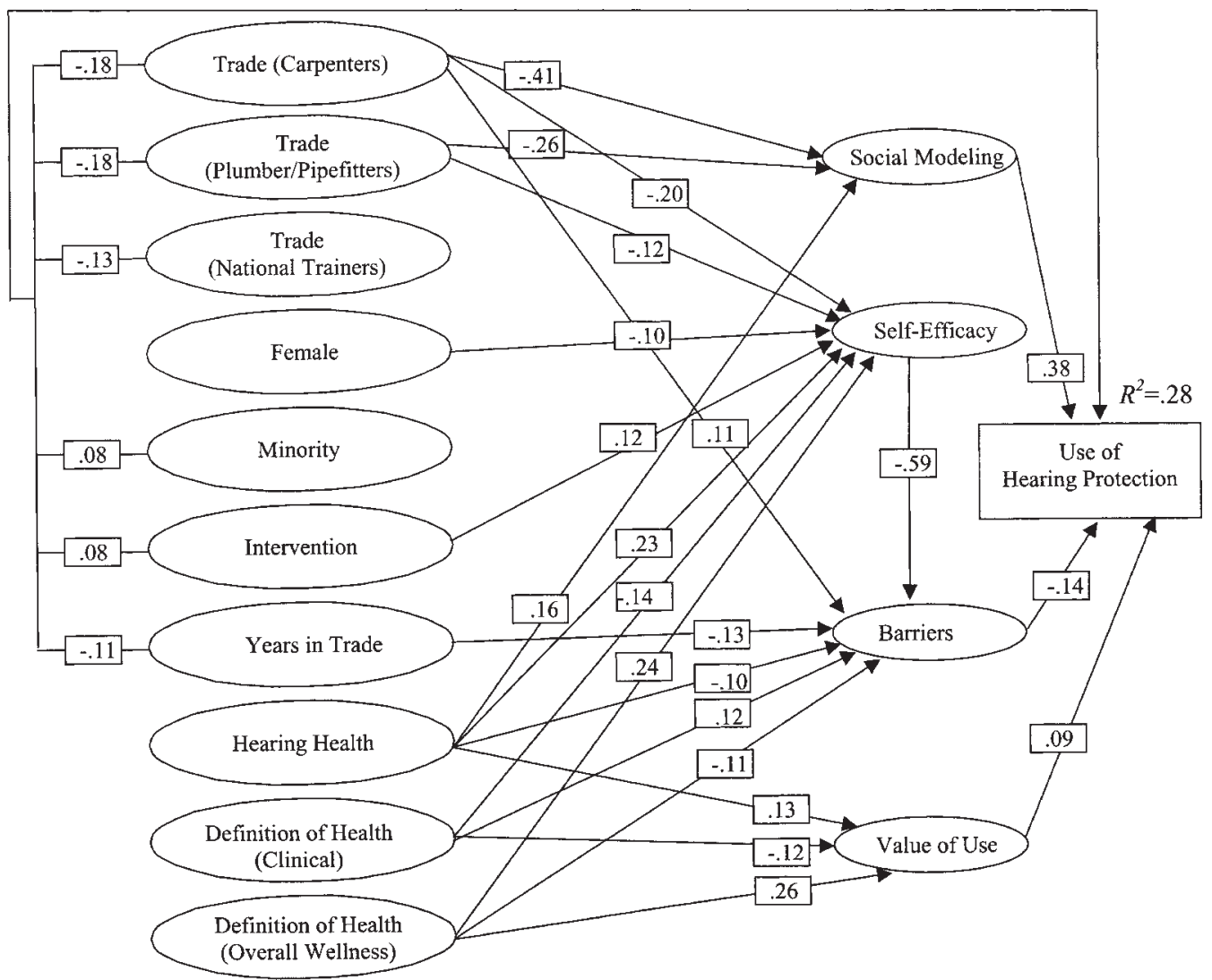

FIGURE 4. Significant paths (revised structure). Path coefficients are standardized and enclosed in boxes. 
specific-variables but dropped the direct paths from the individual characteristics to use of hearing protection. This more constrained variation of the revised form of the HPM had five direct paths to use of hearing protection.

The statistically significant paths in the revised constrained model are shown in Figure 5. This more constrained variation of the revised form of the HPM could also be rejected as a perfect fit to the data, $\chi^{2}(159)=288.4, p<.001$. The practical measures suggest that the fit was good $(\mathrm{NNFI}=.96$; $\mathrm{CFI}=.98$; $\mathrm{RMSEA}=.034)$. The constrained version of the model accounted for $26 \%$ of the variance in use of hearing protection, more than accounted for by the original structure of the HPM (18\%), although not as much as accounted for by the revised form of the HPM $(28 \%)$. Table 4 compares the fit of three structural forms of the HPM; original, revised, and the constrained variation of the revised model. All measures indicate the best fit and predictive accuracy for the revised structure, slightly worse fit and predictive accu- racy for the constrained variation of the revised structure, and notably worse fit and less predictive accuracy for the original structure. Because the constrained variation of the revised HPM accounted for more of the variance in use than the original HPM, although including fewer direct paths to use, these results indicate that the improved explanatory power of the revised form of the HPM is not just due to the increased number of direct paths to use of hearing protection, but primarily is due to the restructuring of the model that put more emphasis on the behavior-specific variables.

\section{DISCUSSION}

The original HPM (Pender, 1987) was revised and restructured (Pender, 1996; Pender et al., 2002), putting a greater emphasis on behavior-specific factors (such as perceived barriers to the target behavior) as direct influences on the behavior. In

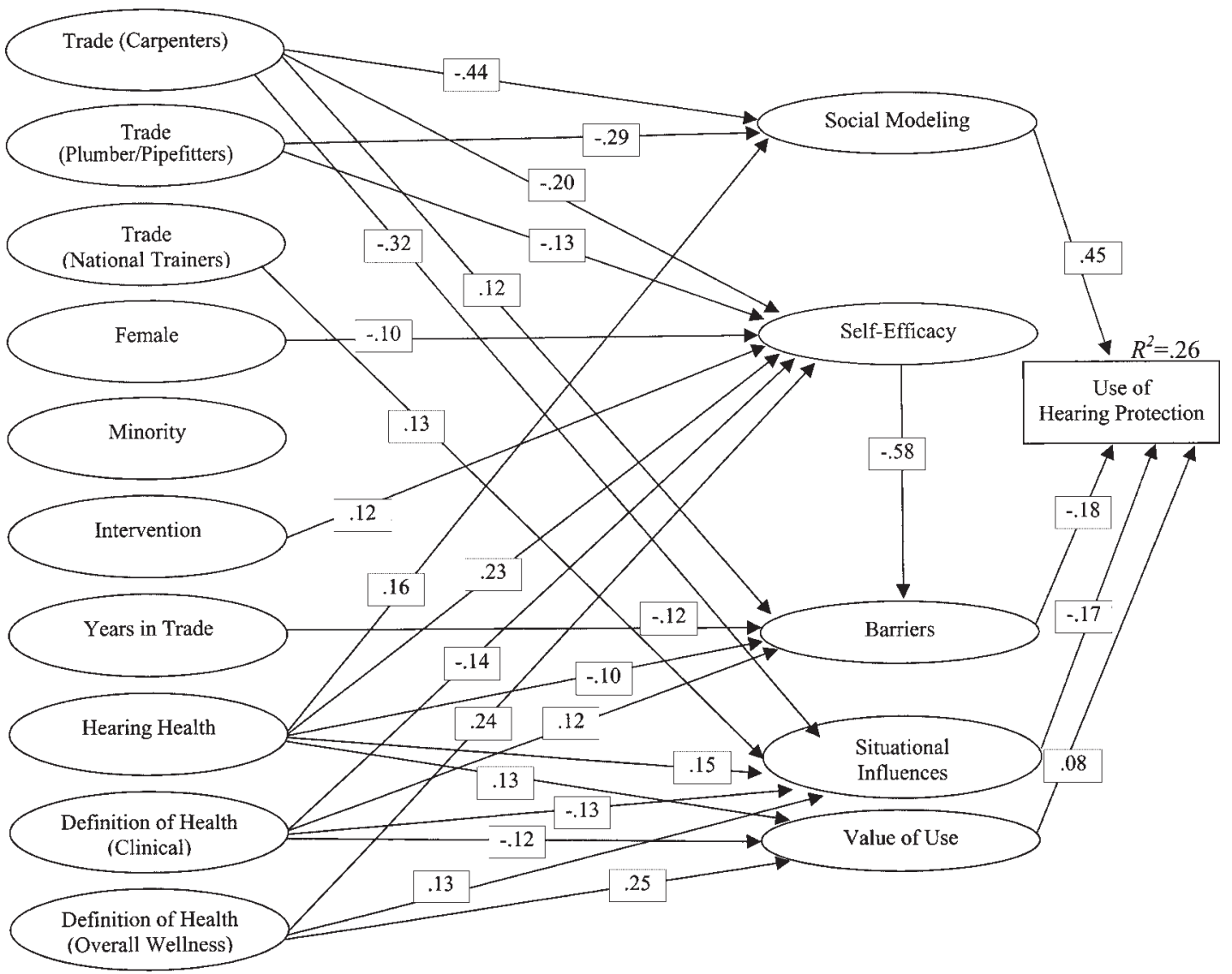

FIGURE 5. Significant paths (revised constrained structure). Path coefficients are standardized and enclosed in boxes. 
the current study, we tested and compared the original and revised structures of the HPM as models of the use of hearing protection by construction workers. The revised structure of the HPM fit better than the original and explained a much higher percentage of the variance in use of hearing protection ( $28 \%$ vs. $18 \%)$.

The strongest predictor of the use of hearing protection in this study was social modeling with a standardized path coefficient of .38 in analysis of the revised structure model. Social modeling was categorized in the original structure of the HPM as a modifying factor and hypothesized not to have a direct path to the behavior. In contrast, the revised form of the HPM categorizes social modeling as a behavior-specific factor, the category emphasized in the revised model as having direct causal paths to behavior. Hence, the strength of this direct path is strong evidence favoring the revised form of the model over the original structure. By making the effect of social modeling on use of hearing protection pass through other variables the original version dramatically underestimated the effect of social modeling on behavior. The total indirect effect of it (.12) in the original structure is much less than the direct effect of it in the revised structure (.38). This strong path also has implications for interventions to increase use of hearing protection. If, as this path suggests, modeling of use of hearing protection by supervisors and others increases use by construction workers, interventions might focus on visible leaders first and encourage all workers to note the use of hearing protection by supervisors. If supervisors do not use (and thus model) hearing protection, this could result in serious hearing loss problems for the entire cohort of workers. The same is likely to be true for other visible health-promoting and healthprotecting behaviors in the workplace. This path to change in behavior though included in the original structure of the model was given much less emphasis.

Another change in the model was dropping the variable perceived control of health. Although this variable was a significant predictor of use of hearing protection devices in analysis of the original model it was a weak predictor. Dropping it from the model and perhaps as a target for intervention appears to be a small loss that the theorist and practitioners can afford although benefiting from greater emphasis on social modeling.

One more change in the model was adding a path from self-efficacy to barriers. This addition was supported by the strongest path in the model $(-.59)$. However the implication of this modification for practice is unclear. Self-efficacy still has an impact on behavior although in our results the effect was fully mediated by barriers. Our intervention gave a lot of attention to overcoming barriers to obtain self-efficacy. That emphasis should continue to be included in interventions.

Other potentially modifiable factors with notable direct or indirect paths to use of hearing protection include: (a) value of use (benefits); (b) barriers to the behavior; and (c) self-efficacy for carrying out the behavior. All of these factors can be targeted in workplace interventions using a combination of information about the benefits of using hearing protection, guidance about how to overcome barriers (such as trying different types of hearing protection to find one that is comfortable), and practice to develop the skills and selfefficacy for correctly using hearing protection and overcoming the barriers. As discussed elsewhere in more detail (Lusk, Hong, et al., 1999; Lusk, Kerr, et al., 1999), the intervention used in this study emphasized development of skills, selfefficacy, and overcoming barriers to use of hearing protection. The estimated structural equation model for the revised form of the HPM shows both a direct effect of the intervention on use of hearing protection and an indirect effect mediated by self-efficacy and barriers.

Several limitations of this study must be acknowledged. First, it should be noted that this study was designed and partially conducted before the publication of the revised HPM (Pender, 1996). The study was not designed specifically for testing the revised structure of the HPM, and does not include a measure of activity-related affect, a variable in the revised model that was not part of the original model. Although this is not a complete test of the revised HPM, it is definitive in showing that the revised structure of the model was better than the original version in accounting for variance in the use of hearing protection.

Second, although the revised structure of the HPM explained a substantial proportion of the variance in the use of hearing protection $\left(R^{2}=.28\right)$ and more than was explained by the original structure of the model $\left(R^{2}=.18\right), 28 \%$ was actually a lower $R^{2}$ than in previous studies using very similar measures in similar populations (Lusk et al., 1997, 1994). Careful comparisons with those previous studies, including re-analyses adding and dropping predictor variables, have not led to an explanation of the lower $R^{2}$ in the current study. One variable that could not be tested in the current study because of its restriction to workers exposed to noise was level of noise exposure. This was a significant predictor of use in the study by Lusk et al. (1997). Yet it does not seem wise to 
expand the study or future research to workers who have no reason to use hearing protection.

Finally, there may be some ambiguity about the interpretation of the modeling variable, which can be viewed as an indicator of worksite culture rather than social influence. We have no data to determine this, but whether it is social influence or worksite culture, it is a behavior-specific measure that contributes to the good fit of the revised form of the model.

In summary, in this study, we compared the fit and predictive usefulness of the original and the revised structures of the HPM to explain the use of hearing protection devices by construction workers. The revised structure of the HPM fit better and explained a substantially higher proportion of the variance in use, supporting the re-organization of the model to put more emphasis on the influence of behavior-specific factors on health-related behaviors. In this study, a behavior-specific factor that was not allowed directly to influence behavior in the original form of the model had the strongest direct path to use, consistent with the re-organization of the HPM. Both structures of the HPM were helpful for understanding the influence of an intervention on use of hearing protection by identifying the partial mediation of the intervention effect by increased self-efficacy and decreased barriers. Assessing the fit of the models and identifying the intervention effects suggest approaches for future interventions to increase use of hearing protection, and offer guidance for the use of the models in designing interventions for other health behaviors.

\section{REFERENCES}

Bandura, A. (1986). Social foundations of thought and action: A social-cognitive theory. Englewood Cliffs, NJ: Prentice-Hall.

Bentler, P.M. (1995). EQS structural equations program manual. Encino, CA: Multivariate Software.

Bollen, K.A. (1989). Structural equations with latent variables. New York: Wiley.

Campbell, D.T., \& Stanley, J.C. (1966). Experimental and quasi-experimental designs for research. Chicago: Rand McNally.

Fishbein, M., \& Ajzen, I. (1975). Belief, attitude, intention, and behavior: An introduction to theory and research. Reading, MA: Addison-Wesley.

Floyd, F.J., \& Widaman, K.F. (1995). Factor analysis in the development and refinement of clinical assessment instruments. Psychological Assessment, 7, 286-299.

Hong, O.S., Lusk, S.L., \& Klem, L. (2000). Factor replication of the reduced Laffrey Health Conception Scale. Journal of Nursing Measurement, 8, 105-116.
Hong, O.S., Wilbur, L.A., \& Furner, S. (1998). Use of hearing protective devices (HPDs) and hearing thresholds among noise exposed Korean airport workers. Journal of Occupational Hearing Loss, 1, 271-279.

Hu, L., \& Bentler, P.M. (1999). Cutoff criteria for fit indexes in covariance structure analysis: Conventional criteria versus new alternatives. Structural Equation Modeling, 6, 1-55.

Johnson, J.L., Ratner, P.A., Bottorff, J.L., \& Hayduk, L.A. (1993). An exploration of Pender's health promotion model using LISREL. Nursing Research, 42, $132-138$.

Kerr, M.J., Lusk, S.L., \& Ronis, D.L. (2002). Explaining Mexican American workers' hearing protection use with the health promotion model. Nursing Research, 51, 100-109.

Laffrey, S.C. (1986). Development of a health conception scale. Research in Nursing and Health, 9, 107-113.

Lusk, S.L., Hong, O.S., Ronis, D.L., Eakin, B.L., Kerr, M.J., \& Early, M.R. (1999). Effectiveness of an intervention to increase construction workers' use of hearing protection. Human Factors, 41, 487-494.

Lusk, S.L., Kerr, M.J., \& Baer, L.M. (1995). Psychometric testing of the reduced Laffrey Health Conception Scale. American Journal of Health Promotion, 9, 220-225.

Lusk, S.L., Kerr, M.J., \& Kauffman, S.A. (1998). Use of hearing protection and perceptions of noise exposure and hearing loss among construction workers. American Industrial Hygiene Association Journal, 59, 466-470.

Lusk, S.L., Kerr, M.J., Ronis, D.L., \& Eakin, B.L. (1999). Applying the health promotion model to development of a worksite intervention. American Journal of Health Promotion, 13, 219-227.

Lusk, S.L., Ronis, D.L., \& Hogan, M.M. (1997). Test of the health promotion model as a causal model of construction workers' use of hearing protection. Research in Nursing and Health, 20, 183-194.

Lusk, S.L., Ronis, D.L., \& Kerr, M.J. (1995). Predictors of hearing protection use among workers: Implications for training programs. Human Factors, 37, 635-640.

Lusk, S.L., Ronis, D.L. Kerr, M.J., \& Atwood, J. (1994). Test of the health promotion model as a causal model of workers' use of hearing protection. Nursing Research, 43, 151-157.

Marsh, H.W., Antill, J.K., \& Cunningham, J.D. (1989). Masculinity and femininity: A bipolar construct and independent constructs. Journal of Personality, 57, 625-663.

Marsh, H.W., Hau, K.-T., Balla, J.R., \& Grayson, D. (1998). Is more ever too much? The number of indicators per factor in confirmatory factor analysis. Multivariate Behavioral Research, 33, 181-220.

McAfee, R.B., \& Winn, A.R. (1989). The use of incentives/feedback to enhance work place safety: A critique of the literature. Journal of Safety Research, 20, 7-19.

National Institutes of Health. (1990). Consensus development conference statement. Noise and Hearing 
Loss 8. Bethesda, MD: US Department of Health and Human Services.

National Institute for Occupational Safety and Health. (1996a). National occupational research agenda (NORA). Washington, DC: US Department of Health and Human Services, Public Health Service, Center for Disease Control and Prevention.

National Institute for Occupational Safety and Health. (1996b). Preventing occupational hearing loss: A practical guide. Washington, DC: US Department of Health and Human Services, Public Health Service, Center for Disease Control and Prevention.

Pender, N.J. (1987). Health promotion in nursing practice (2nd ed.) Norwalk, CT: Appleton \& Lange.

Pender, N.J. (1996). Health promotion in nursing practice (3rd ed.) Stamford, CT: Appleton \& Lange.
Pender, N.J., Murdaugh, C.L., \& Parsons, M.A. (2002). Health promotion in nursing practice (4th ed.) Upper Saddle River, NJ: Prentice Hall.

Ratner, P.A., Bottorff, J.L., Johnson, J.L., \& Hayduk, L.A. (1994). The interaction effects of gender within the health promotion model. Research in Nursing and Health, 17, 341-350.

Ratner, P.A., Bottorff, J.L., Johnson, J.L., \& Hayduk, L.A. (1996). Using multiple indicators to test the dimensionality of concepts in the health promotion model. Research in Nursing and Health, 19, 237247.

Smith, M.S., Wallston, K.A., \& Smith, C.A. (1995). The development and validation of the Perceived Health Competence Scale. Health Education Resource, 10, 51-64. 